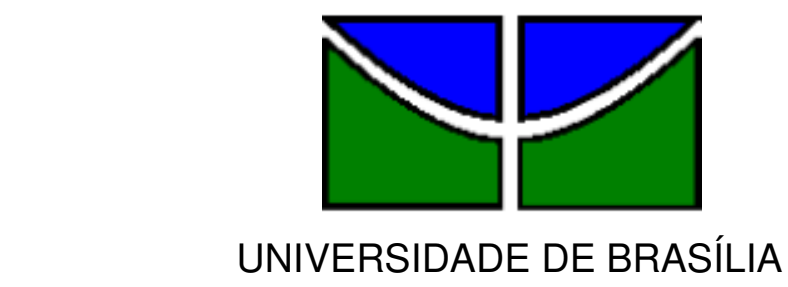

Faculdade de Educação - UAB/UnB/MEC/SECAD

Curso de Especialização em Educação na Diversidade e

Cidadania, com ênfase em EJA

ADRIANA MARIA ALMEIDA BELESK

MAGDA ALVES COSTA SIQUEIRA

\title{
A PRODUÇÃO, ,INTERPRETAÇÃO E MEMORIZAÇÃO DOS ALUNOS DA EJA
}

ANÁPOLIS, GO

Junho/2010 


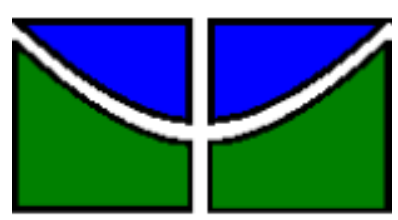

UNIVERSIDADE DE BRASÍLIA

Faculdade de Educação - UAB/UnB/MEC/SECAD

Curso de Especialização em Educação na Diversidade e

Cidadania, com ênfase em EJA

\title{
A PRODUÇÃO, INTERPRETAÇÃO E MEMORIZAÇÃO DOS ALUNOS DA EJA
}

\author{
ADRIANA MARIA ALMEIDA BELESK \\ MAGDA ALVES COSTA SIQUEIRA
}

Projeto de Intervenção Local apresentado para conclusão do Curso de Especialização em Educação na Diversidade e Cidadania, com Ênfase em EJA pela Universidade de Brasília (UNB) por meio da Universidade Aberta do Brasil (UAB) Turma J, como parte dos requisitos necessários para obtenção do grau de Especialista na Educação de Jovens e Adultos sob a orientação da Profa . Ms a .Juliana Alves de Araújo Bottechia e Profá. Drª. Maria Margarida Machado. 


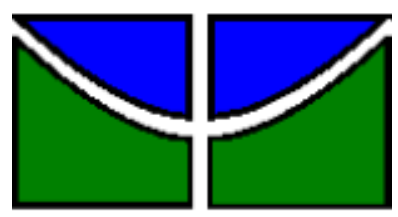

UNIVERSIDADE DE BRASÍLIA

Faculdade de Educação - UAB/UnB/MEC/SECAD

Curso de Especialização em Educação na Diversidade e

Cidadania, com ênfase em EJA

\author{
ADRIANA MARIA ALMEIDA BELESK \\ MAGDA ALVES COSTA SIQUEIRA
}

\title{
A PRODUÇÃO, ,INTERPRETAÇÃO E MEMORIZAÇÃO DOS ALUNOS DA EJA
}

Trabalho de conclusão do Curso de Especialização em Educação na Diversidade e Cidadania, com Ênfase em EJA, como parte dos requisitos necessários para obtenção do grau de Especialista na Educação de Jovens e Adultos.

\begin{tabular}{c}
$\begin{array}{c}\text { Prof }{ }^{-} \text {. Doutora Maria Margarida Machado } \\
\text { (Professora Orientadora) }\end{array}$ \\
\hline $\begin{array}{c}\text { Prof }{ }^{-} \text {. Juliana Alves de Araujo Bottechia } \\
\text { (Tutor Orientador) }\end{array}$ \\
Prof ${ }^{\text {a }}$ Márcia Castilho de Sales \\
(Avaliador Externo) \\
Anápolis, GO
\end{tabular}


BELESK, Adriana Maria Almeida.

A Produção,Interpretação e Memorização dos alunos da EJA / Adriana Maria Almeida Belesk; Magda Alves costa Siqueira - Anápolis: UnB, 2010.

$30 f$.

Orientadora: Prof. Ms. Juliana Alves de Araújo Bottechia

Projeto de Intervenção Local - Universidade de Brasília, Faculdade de Educação $\mathrm{UAB} / \mathrm{UnB} / \mathrm{MEC} / S E C A D$, Curso de Especialização em Educação na Diversidade e Cidadania, com Ênfase em EJA.
1.Escola. 2.Educando.
3. EJA

I. Título. 


\section{AGRADECIMENTOS}

A Deus todo poderoso que nos deu a vida. A nossa família que nos apoiaram. Aos professores que com sabedoria nos ensinaram a seguir este caminho e com paciência nos motivaram a não desistir nas dificuldades. Aos colegas que nessa caminhada nos deram palavras de força e carinho, exemplo de vida e compartilharam experiências. 
"Ninguém educa ninguém, ninguém educa a s i mesmo, os homens se educam entre si ,mediatizados pelo mundo."

Paulo Freire 


\section{RESUMO}

Este projeto tem por objetivo intervir na aprendizagem dos educandos da EJA, tentando diminuir as dificuldades apresentadas pelos mesmos na escrita e leitura, realizado no CEJA professor Elias Chadud onde a clientela da escola é homogenia e diversificada formada por: trabalhadores que buscam um cargo ou um emprego melhor, donas - de - casa que estão cansadas de viverem dependentes do esposo, jovens que querem passar em um concurso ou um vestibular e infratores que são reeducados para voltarem a sociedade em busca de uma vida melhor, busca-se então mostrar não só a importância da leitura de um texto mas a leitura do mundo, além de destacar a interpretação não como um meio de aprendizagem ,mas como forma de interpretar a leitura do mundo. Espera-se que esse projeto contribua para a mudança na maneira de escrever e ler como forma de auxiliar na busca de um emprego ou mudança de vida.

Palavras-Chaves: Escola, educandos, EJA, aprendizagem. 


\section{SUMÁRIO}

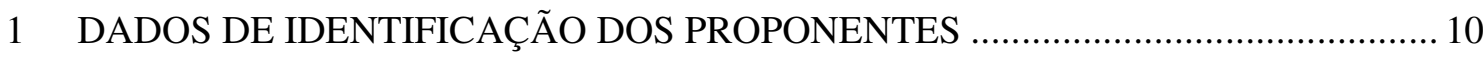

$1.1 \quad$ NOMES

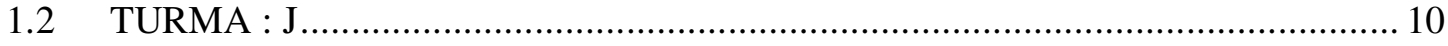

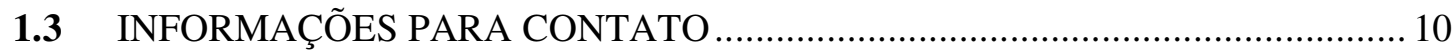

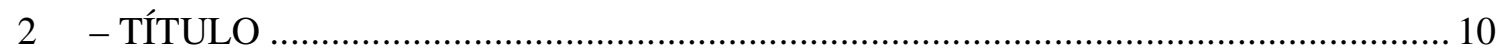

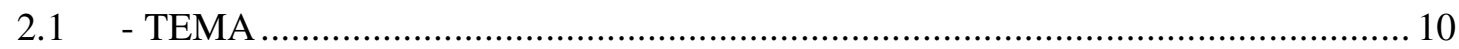

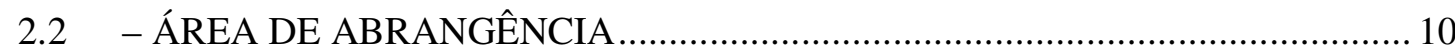

2.3 - INSTÂNCIA INSTITUCIONAL DE DECISÃO ……………………….......... 11

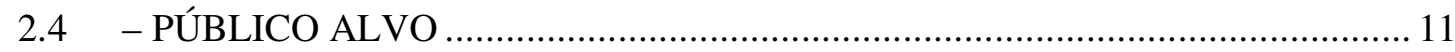

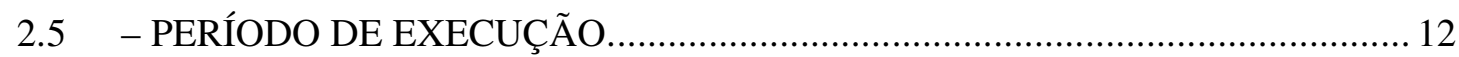

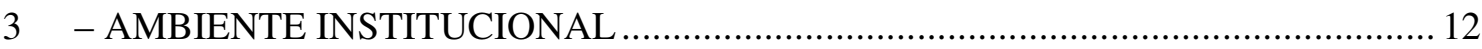

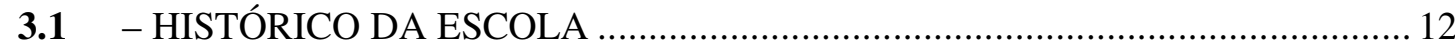

4 - JUSTIFICATIVA E CARACTERIZAÇÃO DO PROBLEMA....................................... 13

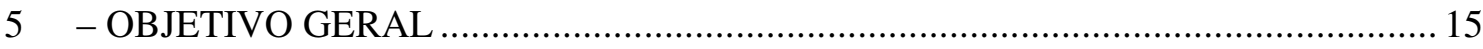

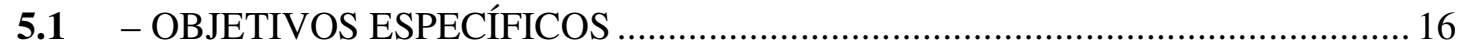

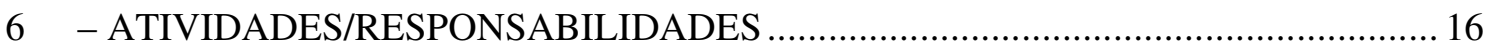

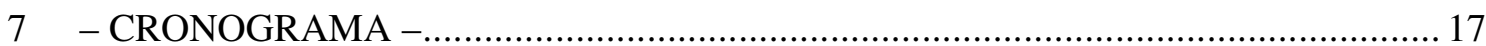

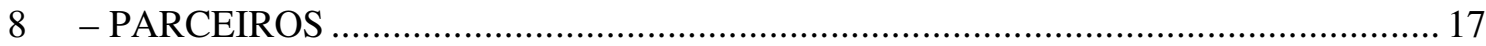

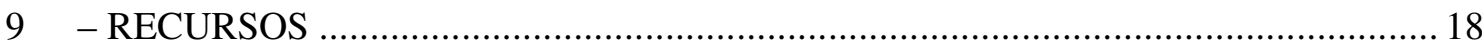

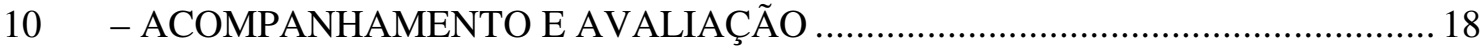

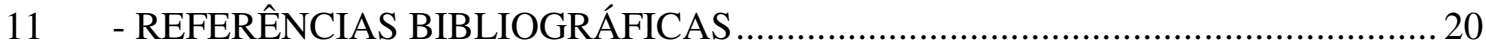

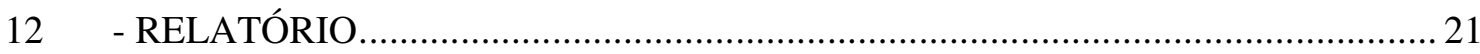

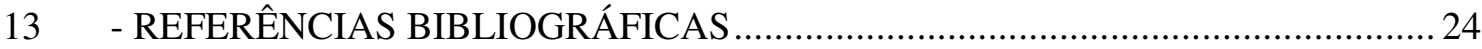

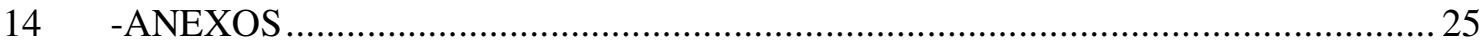

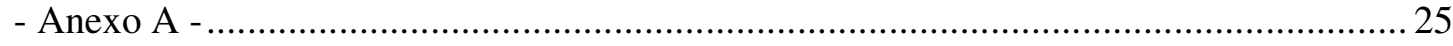

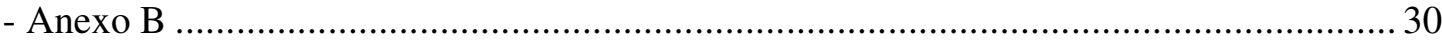

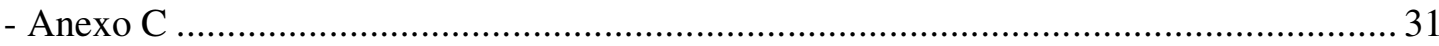




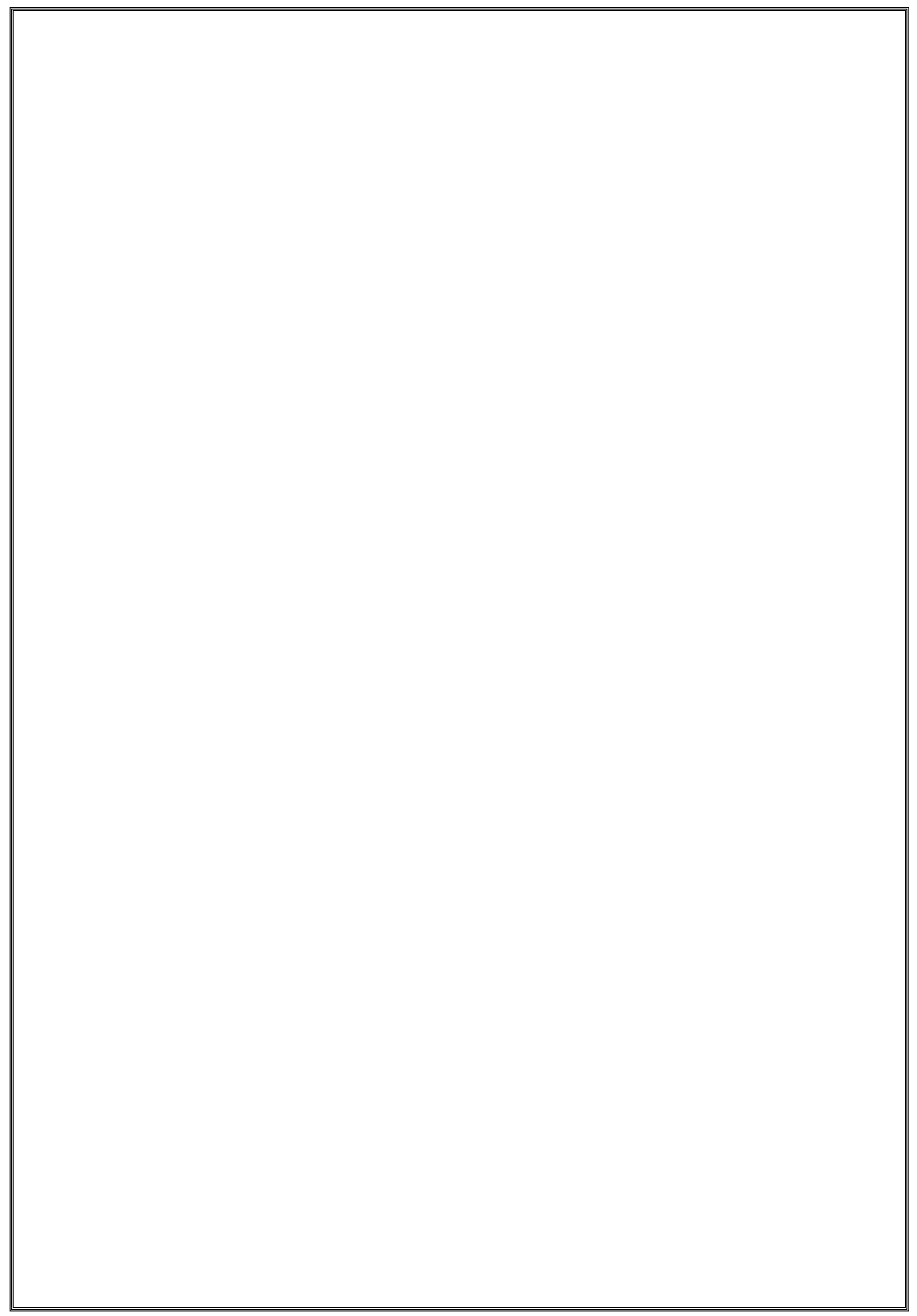




\section{1 - DADOS DE IDENTIFICAÇÃO DOS PROPONENTES}

\subsection{NOMES}

ADRIANA MARIA ALMEIDA BELESK

MAGDA ALVES COSTA SIQUEIRA

1.2 TURMA : J

\subsection{INFORMAÇÕES PARA CONTATO}

Rua 1 Q.11 LT. 07 Vila Norte - Tel. (62)927219

email:d rian abelesk@hotmail.com/drianabelesk@gmail.com adbeleskprofessora@hotmail.com

Rua Antúrio Q.07 Lt.21 Jardim dos Ipês -Tel. (62) 85856601

email: magda.acsiqueira@hotmail.com

\section{2 - TÍTULO}

A Produção,Interpretação e Memorização dos alunos da EJA

$2.1-$ TEMA

Alfabetização e letramento

\section{2 - ÁREA DE ABRANGÊNCIA}

Nível de abrangência local no Centro de Educação para Jovens e Adultos Professor Elias Chadud localizado na Avenida das Nações N01 - Jardim Bandeirantes- Cep: 75083050 ,Anápolis - Goiás.Mantido pela Secretária Estadual de Educação de Goiás,atuando somente na Educação de Jovens e Adultos nos períodos matutino, vespertino e noturno. 


\section{3 - INSTÂNCIA INSTITUCIONAL DE DECISÃO \\ - Escola Estadual e Conselho Escolar \\ - Diretora \\ - Coordenadores \\ - Professores}

- Alunos da EJA

\section{4 - PÚBLICO ALVO}

Trata-se de um terço da população brasileira - isso é um volume assustador e, ao mesmo tempo desafiador de, não apenas responder com uma escola pública, gratuita, laica e de qualidade, mas, sobretudo, com um sistema de educação, no Brasil, orgânico, em que essa escola responda à diversidade de sujeitos de saberes, de sujeitos aprendizes, superando as desigualdades. . (Orientação para elaboração do projeto de intervenção local,p.03)

Jovens e adultos trabalhadores acima de 15 anos que mostraram deficiência na leitura, interpretação e produção de texto, devido ao não acesso ou continuidade de estudo na época certa.

A educação de jovens e adultos será destinada àqueles que não tiveram acesso ou continuidade de estudos no ensino fundamental e médio na idade própria. (Lei de Diretrizes e Bases Seção V : Da Educação de Jovens e Adultos - art.37)

Os educandos são formados por jovens que buscam passar em um concurso ou vestibular e tentam recuperar o tempo perdido, donas-de-casa que estão cansadas de viverem dependentes dos esposos ou têm filhos na escola e estudam para ajudá-los nas tarefas, jovens e adultos infratores que são reeducados para ingressarem novamente na sociedade e buscar melhorias, trabalhadores que querem um cargo melhor na empresa ou buscam um emprego melhor através de concursos, os educandos são bem diferenciados não só na idade , raça ou cor, mas na classe social, nos objetivos da aprendizagem e nos desejos de melhorar de vida, alguns tentam elevar a sua autoestima através de recupaerar o tempo perdido e uma parte dos educandos buscam elevar sua escolaridade como afirma 
Laurenice Frazão Guedes no seu texto "A leitura no Universo Educacional de Jovens e Adultos":

Uma parte dos alunos, ao ingressar nessa modalidade especial de educação, procura programas de elevação de escolaridade, em sua maioria,buscando melhorar suas chances para ingressar no mercado de trabalho, ou seja,objetiva, claramente, um certificado formal do nível de estudos alcançados. Outra parte ingressa pela razão de buscar reconhecimento social e de afirmar a sua autoestima .Enfim, são diversas as motivações que levam os alunos da EJA de volta aos estudos ou ao ingresso pela primeira vez na sala de aula.

\section{5 - PERÍODO DE EXECUÇÃO}

Fevereiro de 2010 com término previsto para Dezembro do mesmo ano.

\section{3 - AMBIENTE INSTITUCIONAL}

\section{$3.1-$ HISTÓRICO DA ESCOLA}

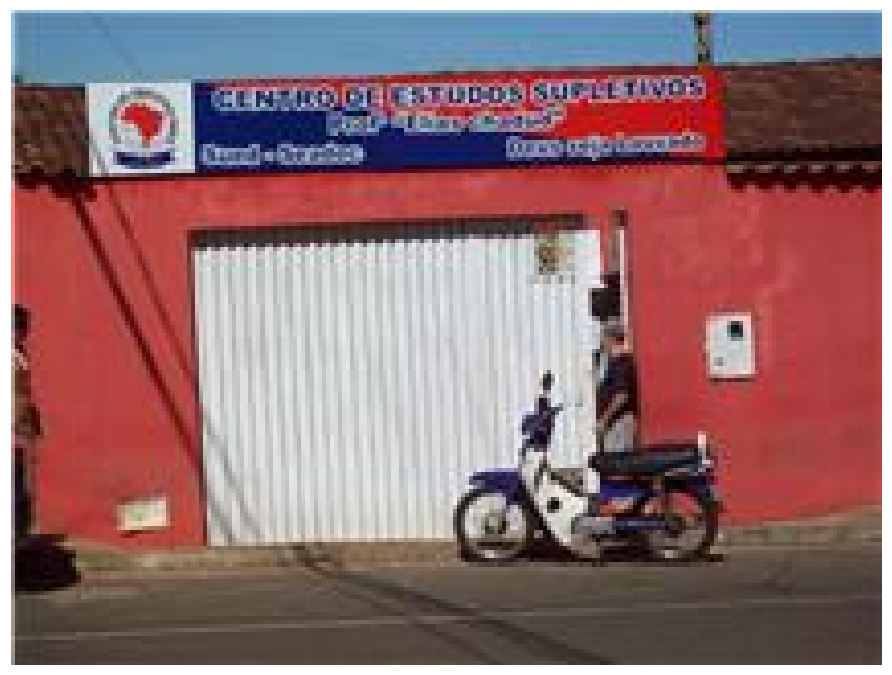

O Centro de Educação para Jovens e Adultos Professor Elias Chadud foi criado pelo decreto lei no 10083/86, com portaria de reconhecimento $n^{\circ} 132 / 01$ ou seja sua autorização de funcionamento só saiu em 2001. A Escola é uma instituição da rede pública estadual, mantida pelo governo do estado de Goiás; oferece a EJA aos cidadãos maiores de 14 anos nas modalidades de I e II etapa do ensino fundamental e III etapa maiores de 18 anos, correspondendo ao Ensino Médio; sendo responsável pela educação ministrada no $4^{\circ}$ batalhão da Polícia Militar ( 4ํㅗㄱ), Presídio de Anápolis e na Extensão do Colégio Manoel Gonçalves. O prédio está situado em uma área central construído pelo Governo no ano de 1986, na gestão de Romualdo Santillo, com uma área de $3400 \mathrm{~m}^{2}$ sendo $1132,58 \mathrm{~m}^{2}$ de área construída. Conta com quatorze salas de aula, uma secretaria, uma sala de coordenação, 
direção e de professores,uma biblioteca e um laboratório de informática com 9 computadores.

A escola funciona nos turnos matutino, vespertino e noturno com total de 1732 alunos matriculados. Oferecendo : ensino fundamental $1^{\text {a }}$ etapa ( $1^{\circ}$ ao $5^{\circ}$ ano $) 2^{\underline{a}}$ etapa ( $1^{\circ}$ ao $6^{\circ}$ semestre) e ensino médio ( $1^{\circ}$ ao $4^{\circ}$ semestre ) conforme resoluções $n^{\circ} 198$ e $n^{\circ} 260$, na modalidade de Educação para Jovens e Adultos ( EJA),com 108 funcionários,sendo 3 do grupo gestor, 6 coordenadores, 58 professores, 3 dinamizadores, 3 bibliotecários. 12 auxiliares administrativos, 15 serviços gerais, 2 vigias, 3 merendeiras e 3 porteiros.

Não apresenta dificuldades relevantes em relação à Estrutura Organizacional; pois todas as ações são previamente elaboradas.

Os planos Curriculares relacionados à nova matriz já se desenvolvem normalmente na rotina escolar. As disciplinas são avaliadas e ministradas conforme os Parâmetros Curriculares Nacionais(PCN); enriquecidos com outros elaborados pelos docentes desta instituição com finalidade de promover uma educação de qualidade, apesar de se trabalhar com alunos de idades, classes sociais e objetivos diferentes, vai da reeducação de jovens e adultos infratores até donas - de - casa, trabalhadores e jovens em busca de passar em concursos e vestibulares.

A partir de 2007 a escola tem trabalhado com vários projetos para melhorar e enriquecer a aprendizagem dos educandos, são projetos de interdisciplinaridade que atende as necessidades dos alunos. Este ano iniciou o projeto resgate em que a escola tenta resgatar os alunos evadidos ou desistentes auxiliando-os ,impedindo então a evasão escolar.

\section{4 - JUSTIFICATIVA E CARACTERIZAÇÃO DO PROBLEMA}

Trabalhar com alfabetização, leitura e interpretação se torna mais fácil para crianças pois ainda estão formando seu contexto sócio - cultural, já com o adulto se torna mais difícil pelo fato dele já ter seu contexto formado, essa dificuldade aumenta mais ainda quando se trata de adultos trabalhadores como o caso da EJA.

Para as crianças, é natural que estejam em processo de aquisição do cotexto e do contexto. Os jovens e adultos, sendo alunos e pessoas, já possuem amplo contexto, geralmente uma história de exclusão social, cultural e autoexclusão. Assim, a responsabilidade de transpor a barreira social por meio do aprendizado da leitura e da escrita da língua materna, além de outros aspectos da cultura e do conhecimento produzido 
socialmente, torna-se muito maior para os professores, para a escola e para eles mesmos. Os alunos adultos sentem-se atrasados e sua busca maior é pelo cotexto, pela parte formal da língua, aquilo que poderá ser avaliado e Ihes dará a nota necessária para a obtenção do diploma. (CARVALHO, 2009)

Os educandos da EJA apresentam dificuldades em interpretar, produzir, ler e memorizar textos, devido ao tempo em que ficou afastado e o pouco estudo obtido então como proceder para que o educando trabalhador use no seu dia-a-dia a leitura e interpretação? É importante , é necessidade que exige sua profissão? Houve uma conversa informal para descobrir realmente o desejo do aluno nesses aspectos ,alguns têm o desejo de entender os ofícios que são mandados pelas empresas,não sabem falar com o patrão e sentem vergonha e não sabem lutar pelos seus direitos por não conhecê-los ou não entendê-los, não sabem quais os pronomes devem usar de acordo com o grau de escolaridade e hierarquia no trabalho, sentem o desejo de fazer uma redação para prestar um concurso ou um vestibular,outros estão apenas dispostos a receberem um diploma de conclusão de ensino médio sem muita preocupação com a aprendizagem,alguns procuram entender coisas simples como interpretar a bíblia, ou ajudar os filhos a lerem, fazerem contas de matemática e para isso precisam interpretar e alguns acreditam que não são capazes de aprender mais nada. Por que há essa necessidade dos alunos em interpretarem o que lêem? Ou expressarem oralmente suas idéias?

O processo de aprendizagem na alfabetização de adultos está envolvida na prática de ler, de interpretar o que lêem, de escrever, de contar, de aumentar os conhecimentos que já têm e de conhecer o que ainda não conhecem, para melhor interpretar o que acontece na nossa realidade. (FREIRE, p. 48)

A leitura, produção e interpretação para o educando da EJA são importantes para aumentar os conhecimentos e para entender o que acontece ao seu redor, a sua realidade,então ele tem que ter um conhecimento não é só para usar no trabalho ou na sua profissão pois ajuda o educando a se expressar melhor em determinadas ocasiões como afirma Leila Chalub em seu texto : "A construção do sujeito pela Educação revistando Paulo Freire" que os jovens e adultos quando voltam a estudar parecem que perderam a "compreensão de si mesmos", falam pouco ou muitas vezes "alguém fala por eles" deixando muitas vezes de se "expressar sua própria vontade e pensamento". Não se pode apenas olhar o que o educando da EJA irá precisar aprender para usar como trabalhador profissional, mas também para usar na sua vida, no seu mundo, ao seu redor e no seu cotidiano. 
Na medida em que os homens, simultaneamente refletindo sobre si e sobre - mundo, vão aumentando 0 campo de sua percepção . (FREIRE,p.41.1987)

Dessa forma sentiu-se a necessidade de criar o Projeto de Intervenção Local em que se busca sanar dificuldades apresentadas pelo aluno de EJA na leitura, interpretação, produção e memorização de textos, dando ao educando condições de ler e entender os textos simples como histórias em quadrinhos,além de aprender a estrutura desses textos, ler e entender textos mais complexos como notícias de jornais, revistas e classificados, além de estudar textos literários e biografias de autores, aprender como se faz e usar correspondências como recibo, ofício, carta comercial, curriculum vitae, solicitação de emprego , pedido de demissão, preenchimento de cheques, promissórias e etc.Aproveitar o que o aluno sabe, pois ele já vem com uma bagagem , o que se faz apenas é enriquecer essa bagagem como forma de melhorar sua vida e até mesmo sua autoestima. Devido suas necessidades de cotidiano, a EJA deve oferecer pelo menos uma formação para inseri o educando no exercício pleno da cidadania e aproveitar as oportunidades no mercado de trabalho, não um salto para se conseguir um diploma de ensino médio.

A necessidade de contínuo desenvolvimento de capacidades e competências para enfrentar essas transformações alterou a concepção tradicional de educação de jovens e adultos, não mais restrita a um período particular da vida ou a uma finalidade circunscrita. Desenvolve-se o conceito de educação ao longo de toda a vida, que há de se iniciar com a alfabetização. Mas não basta ensinar a ler e a escrever. Para inserir a população no exercício pleno da cidadania, melhorar sua qualidade de vida e de fruição do tempo livre e ampliar suas oportunidades no mercado de trabalho, a educação de jovens e adultos deve compreender no mínimo, a oferta de uma formação equivalente às oito séries iniciais do ensino fundamental. (Plano Nacional de Educação,p.50)

Deve-se mostrar ao aluno a necessidade de se ter uma linguagem do mundo em que se consegue apenas com o ler e escrever pois são indispensáveis ao ser humano e é claro que não se pode ignorar o que a vida ensinou ao educando, tem que se valorizar o aprendizado que o nosso aluno traz da sua caminhada vivida, e como afirma Leila Chalub: "É a linguagem que assegura a existência do mundo cultural. É pela linguagem que o mundo cultural é construído."

\section{5 - OBJETIVO GERAL}

Ampliar o interesse dos alunos quanto a leitura e a produção textual individual, bem como melhorar a leitura de mundo num coletivo enquanto indivíduo parte de uma sociedade crítica. 


\section{1 - OBJETIVOS ESPECÍFICOS}

- Aumentar a competência comunicativa do aluno;

- Estimular o gosto pela leitura e escrita;

- Ler e analisar textos de memórias;

- Produzir textos e paródias individualmente e em grupo;

- Explorar fatos do cotidiano;

- Desenvolver pesquisas com o uso da internet.

\section{6 - ATIVIDADES/RESPONSABILIDADES}

Vygotsky acreditava que o bom ensino é aquele que investe no que o aluno ainda pode aprender, desde que tenha ajuda. Acreditava também na ação coletiva como transformadora das classes sociais e da pessoa e isso acontece pela linguagem, pois é através da linguagem que o ser humano pode trocar mensagens, construir significados e pensar.

Assim, foi desenvolvido atividades com ajuda de professores de português, em que o aluno pudesse usar melhor a sua linguagem através de apresentação de paródias, leitura de textos diversos com interpretação para enriquecimento de vocabulário, ampliando a sua capacidade crítica e de pensamento.

Criação de cartazes, banners, faixas e panfletos e exposição dos mesmos;com ajuda dos professores de português, biologia, inglês, matemática, filosofia,história e geografia, visando entender como é um texto informativo para que serve o texto informativo e aprender como se deve passar a informação para outros compreenderem.

Produção de textos variados e apresentação em forma de teatro de fantoches, permitindo que o aluno aprenda a trabalhar em grupo, dividindo tarefas, desenvolvendo a oralidade, a escrita e a curiosidade.

O educador que castra a curiosidade do educando em nome da eficácia da memorização mecânica do ensino dos conteúdos, tolhe a liberdade do 
educando, a sua capacidade de aventurar-se. Não forma, domestica.(FREIRE,63.1997)

Exploração de reportagens de jornais, anúncios de lojas, revistas, anúncios, avisos, correspondências : desde a carta particular até a comercial, ofícios, curriculum vitae, recibos, cheques,promissórias,solicitação de emprego, pedido de demissão etc.

- Interação com o aluno, fazendo-o sentir-se útil para si e para a sociedade a qual ele pertence.

- Apresentações artísticas no pátio da escola, pelos alunos e pela comunidade escolar.

- Produção de avisos da escola.

\section{7 - CRONOGRAMA -}

Atividades desenvolvidas por professoras e alunos.

\begin{tabular}{|l|c|}
\hline \multicolumn{1}{|c|}{ ATIVIDADES } & PERÍODO \\
\hline Início do Projeto & Fevereiro \\
\hline Atividades de leituras & $1^{1^{a}}$ quinzena de março \\
\hline Produção de portfólios & Abril \\
\hline Produção de cartazes, banners, faixas e panfletos & $1^{\text {a⿱⺈}}$ quinzena de maio \\
\hline Apresentação do teatro de fantoches & $1^{1^{a}}$ quinzena de Março \\
\hline $\begin{array}{l}\text { Apresentação artísticas dos alunos e exposição dos } \\
\text { banners, cartazes e panfletos }\end{array}$ & Agosto e Setembro \\
\hline $\begin{array}{l}\text { Exploração de reportagens de jornais, anúncios de } \\
\text { lojas, revistas, anúncios, avisos, cartas, etc. }\end{array}$ & Agosto a Novembro \\
\hline Produção de avisos da escola. & Dezembro \\
\hline Finalização do projeto & \\
\hline
\end{tabular}

\section{8 - PARCEIROS}

- Diretora;

- Coordenadora; 
- Professores;

- Alunos.

\section{9 - RECURSOS}

- Materiais didáticos disponíveis na escola;

- Aparelhos tecnológicos;

- Laboratório de informática;

- Biblioteca.

- Cartazes, banners, panfletos e faixas

\section{0 - ACOMPANHAMENTO E AVALIAÇÃO}

O projeto permitiu que o educador trabalhasse como Paulo Freire costumava afirmar em seus livros: "facilitador do saber" e não como donos do saber,os alunos foram auxiliados ao longo do $1^{\circ}$ semestre e desenvolveram bem as atividades propostas do projeto :

1- Mostraram uma criatividade inesperada ao produzirem textos, principalmente no teatro de fantoches, fizeram textos modernos com fundo de moral, textos de informação e preservação. Alunos que eram muito quietos e calados mostraram verdadeiros atores e passaram a se comunicaram com o grupo, deram idéias e foram os melhores na oralidade quando dramatizaram as histórias. Nas paródias, também demonstraram criatividade cantando, houve uma melhoria nos alunos calados, se tornaram mais participativos e mais expansivos.

Por isto é que esta educação, em que educadores e educandos se fazem sujeitos do seu processo, superando o intelectualismo alienante, superando o autoritarismo do educador "bancário", supera também a falsa consciência do mundo.(FREIRE,p.43,1987)

2- Inicialmente mostraram dificuldades em desenvolver algumas atividades por estarem acostumados com atividades mecanizadas e decorativas, e alguns acreditavam que não eram capazes de desenvolver nenhuma, pois as mesmas exigiam reflexão, atenção , leitura, pesquisa e autocritíca sendo que eles tem dificuldades em falar o que pensam e os textos estudados e a produção de textos exigiam que o educando comentasse ou desse sua 
opinião. "Não é no silêncio que os homens se fazem, mas na palavra, no trabalho, na açãoreflexão". (FREIRE, p.44,1987)

3 - Desempenharam as ações sugeridas pelos professores e participaram ativamente nas aulas, através das leituras dos textos em que muitos no início tinham dificuldades em ler e por isso sentiam envergonhados, aos poucos perceberam que todos tinham dificuldades e passarem a participar das leituras, das atividades escritas como as construções de frases, períodos e orações, aprenderam a diferenciar verbos e a usarem a concordância adequada,compararam faixas e cartazes usados em lojas e casas reconhecendo os desvios da língua como : "Vende-se bombons", "Àpartir" etc.Refletiram sobre a importância de interpretar adequadamente cada frase lida.

4 - As deficiências apresentadas na escrita e na oralidade não foram totalmente sanadas pois são aspectos demorados exige tempo, paciência e desempenho mas devido ao desenvolvimento do projeto pode -se recuperar um pouco dessas deficiências, e foi muito gratificante pois mostrou onde estavam as falhas e o que pode-se esperar de nosso aluno.Isso mostra o quanto é importante trabalhar com projetos. 


\section{1 - REFERÊNCIAS BIBLIOGRÁFICAS}

ASSOCIAÇÃO BRASILEIRA DE NORMAS TÉCNICAS. NBR 6023: informação e documentação: referências: elaboração. Rio de Janeiro, 2002.

CHALUB, Leila Martins. A construção do sujeito pela educação. Revisando Paulo Freire.

DIDÁTICA interpretação de texto com jovens e adultos ,23 jun. 2009 ... A Interpretação de Textos na Educação de Jovens e Adultos. Disponível em <

http://www.educacaopublica.ri.gov.br/suavoz/0124.html >.Acesso em 25 jun.2010

FREIRE, Paulo. Pedagogia do Oprimido. 20ª Edição. Rio de Janeiro: Paz e Terra, 1987.

Pedagogia da indagação. São Paulo: Ed. UNESP, 2000.

22.ed., São Paulo: Cortez,1988. 80 .

Pedagogia da autonomia: saberes necessários à prática educativa. São

Paulo: Paz e Terra, 2004.

Educação como prática para liberdade. Rio de Janeiro: Paz e Terra,

1989.

LDB: Leis de Diretrizes e Bases. Lei $N^{\circ} 9.394$ de 20 de dezembro de 1996. Disponível em: <http://www.planalto.gov.br/ccivil 03/LEIS/l9394.htm>. Acesso em: 25 jun.2010.

GUEDES ,Laurenice Frazão. A leitura no Universo Educacional de Jovens e Adultos. Disponível em < http://www.alb.com.br/anais17/txtcompletos/sem02/COLE 4216.pdf > Acesso em 25 jun.2010

REVISTA nova escola- Especial Grandes Pensadores -Lev Vygotsky. Disponível em< http://revistaescola.abril.com.br/historia/pratica-pedagogica/lev-vygotsky-teorico$\underline{423354 . s h t m l}$ >. Acesso em 28 jun.2010

VYGOTSKY,L.S. Pensamento e Linguagem. São Paulo, Martins Fontes,1993. Disponível em< http://www.ebooksbrasil.org/eLibris/vigo.html >. Acesso em 28 jun.2010 


\section{2 - RELATÓRIO}

Aos orientadores da Universidade de Brasília - UNB

Especialização em Educação na Diversidade e Cidadania, com ênfase na EJA

Brasília - DF

Relatório de experiência : Roteiro básico

Cidadania é a qualidade, ou o estado de cidadão. Cidadão, por seu turno, não significa ser habitante de uma cidade, como era originalmente (em contraste com a aldeia), mas, ser alguém no gozo dos direitos civis e políticos de um Estado e no desempenho de seus deveres para com esse mesmo Estado. O gozo desses direitos e o desempenho desses deveres são estabelecidos e delimitados por um conjunto de formalidades que devem ser observadas entre si pelos cidadãos, em sinal de respeito mútuo e consideração, conduzindo-os a um alto grau de civilidade, condição necessária para uma sociedade prosperar em meio à paz e à concórdia. (CARDOSO,Ernesto,2007,2ed. revisto)

O aluno da EJA busca sua cidadania ,seus direitos quando retorna aos estudos, um desses direitos é a capacidade de ler, entender o que escreve e o que ler e as condições de produzir textos em que demonstre suas idéias, seus pensamentos.

Para o sujeito construir a habilidade de escrever e ler é necessário que compreenda a sua própria existência. É preciso ter consciência de que a escrita tem por função registrar fatos criados e vividos pelo homem. A escrita registra os significados dos homens. (ABDALA, Nacir)

Sempre teve-se dificuldades em trabalhar com o aluno da EJA devido às deficiências apresentadas por causa da má alfabetização, do não saber ler e entender o que escreveu, o pior é que muitos por acreditarem que já estão velhos não tinham mais a capacidade de aprender, em seguida surgia outras dificuldades, como usar uma apostila fora da realidade do aluno se é material adotado pela escola? Tinha que seguir o que era determinado no planejamento. Outra dificuldade encontrada era o desinteresse de alguns professores em ajudar o aluno na leitura e interpretação, por acreditarem que isso era de responsabilidade do professor de português. Hoje ao perceberem que essa deficiência precisa da ajuda de todos para saná-la muitos principalmente professores de história, sociologia , filosofia e geografia estão trabalhando esses aspectos.

O educando se aperfeiçoa a medida que domina a língua escrita e oral, ele enriquece e desenvolve seu intelecto e sua cultura, ele se transforma, transforma sua história de vida, 
é o meio em que ele encontra de se comunicar melhor e de entrar na sociedade de cabeça erguida.Assim como afirma Abdala:

Deve-se também esclarecer que a escrita é vista como um processo de aperfeiçoamento do homem, um enriquecimento exterior, um desenvolvimento intelectual e cultural do ser humano. O domínio da língua oral e escrita é fundamental para a participação social efetiva, pois é por meio dele que o homem se comunica, tem acesso a informações, expressa e defende pontos de vista, partilha ou constrói visões de mundo, produz conhecimentos.( ABDALA, Nacir)

Surge a necessidade de se criar um projeto. No início houve a dificuldade em encontrar um projeto adequado pois a escola vem desenvolvendo projetos para ajudar na aprendizagem dos alunos desde 2007, então pensou em trabalhar na área de língua portuguesa e colocou-se em prática o Projeto de Intervenção Local: A Produção, Interpretação e Memorização dos Alunos da EJA .Conforme especificado abaixo:

01 -Primeiramente teve-se que trabalhar com os alunos retirando da mente deles a idéia de achar que não conseguem mais aprender, houve uma conversa informal entre professores e alunos em que os mesmos disseram o que tinham vontade de aprender na língua portuguesa, mostraram suas dificuldades e seus anseios e desejos .

02 - Foi ensinado ao aluno como construir frases, mostrando a estrutura das mesmas como o verbo, substantivo, adjetivo, explicando a finalidade de aprender a morfologia e a sintaxe. Alguns alunos não sabiam nem reconhecer o verbo nas frases, com as atividades passaram a identificá-lo e entenderam o uso do plural e do singular pela concordância.

03 - Trabalhou-se com textos diversificados como : histórias em quadrinhos, contos, fábulas, textos sobre assuntos atualizados, além de músicas, correspondências, fazendo a leitura ,interpretação através de discussão e em seguida o aluno produzia seu próprio texto.O teatro de fantoches foi desenvolvido em quatro dias: no $1^{\circ}$ dia : Dividiu-se o grupo, a sala escolheu como seria o cenário, em seguida foi escolhido os temas e depois os bonecos. No $2^{\circ}$ dia: O grupo discutiu o tema, escolheu e escreveu a história e dividiu as tarefas. No $3^{\circ}$ dia :A professora corrigiu os textos, e em seguida os alunos ensaiaram. No $4^{\circ}$ dia : Houve a apresentação.Pretende-se ainda continuar trabalhando textos de jornais, revistas,anúncios e cartas, além de produção de anúncios da escola feitos pelos alunos.

04 - Como a escola desenvolve um projeto todos os anos, projeto interdisciplinar sendo que este ano foi sobre o "Aquecimento Global, verdade ou mentira", participamos ee os alunos tiveram a oportunidade de produzir banners, faixas, panfletos, textos informativos 
com a finalidade de passar informações de como evitar o aquecimento global além de expôlos.

05 - Foi desenvolvido produções de textos em que os alunos apresentaram em forma de teatro de fantoches, e paródias visando desenvolver o trabalho em grupo, como dividir tarefas, desenvolver a oralidade e a leitura, mostrando que eles são capazes de aprender e de desenvolver bem a escrita, além de elevar sua auto - estima.

O objetivo foi alcançado de acordo com o que foi programado, visto que falar, ler e escrever é um processo complexo, demorado, exige muito tempo, dedicação e até mesmo paciência por se tratar de aluno de EJA visando pouco tempo para dedicar devido o excesso de trabalho e atividades do dia- a- dia. Levando em consideração que todo objetivo alcançado requer luta, garra e perseverança.

Mais uma vez os homens, desafiados pela dramaticidade da hora atual, se propõem, a si mesmos, como problema. Descobrem que pouco sabem de si, de seu "posto no cosmos", e se inquietam por saber mais. Estará, aliás, no reconhecimento do seu pouco saber de si uma das razões desta procura. Ao instalar-se na quase, senão trágica descoberta do seu pouco saber de si, se fazem problema a eles mesmos. Indagam. Respondem, e suas respostas os levam a novas perguntas. (FREIRE,1987.p.16)

Anápolis, 10 de Junho de 2010.

ADRIANA MARIA ALMEIDA BELESK

MAGDA ALVES COSTA SIQUEIRA 


\section{3 - REFERÊNCIAS BIBLIOGRÁFICAS}

ABDALA, Nacir. Concepções de leitura e de escrita. Disponível em $<$ http://www.educacional.com.br/articulistas/outrosEducacao artigo.asp?artigo=artigo0069 > Acesso em 08 jul.2010

CARDOSO, Ernesto. Cidadania - seu significado. Disponível em $<$ http://www.ubaweb.com/revista/g mascara.php?grc=14136 $>$ Acesso em 08 jul.2010

FREIRE, Paulo. Pedagogia do Oprimido. 20를 Edição. Rio de Janeiro: Paz e Terra, 1987. 


\section{4 -ANEXOS}

- Anexo A - Discutir assuntos atuais como o aquecimento global, o racismo, a preservação do meio ambiente, o combate a doenças, produzir textos e apresentar através de teatro de fantoches.

\section{Racismo no Brasil}

\section{Personagens:}

$>$ Narrador:

$>$ Negro:

$>$ Segurança:

D Loira:

Encontraram em uma loja uma loira e um negro. Os dois pegaram objetos da loja. Ao sair o alarme apitou e veja o que aconteceu.

O Segurança :_Pare, pare que queremos fazer uma revista em suas coisas negro.

O Negro indaga:_ Mas saiu uma loira junto comigo, por que ela não vai ser revistada?

A Loira :_Eu não peguei nada, posso ir?

O Segurança : _ Você está libertada, creio que foi o negro que roubou. Desculpe-nos pelo incomodo.

Narrador: Moral da História: os dois pegaram objetos mais pelo grande preconceito somente o negro foi acusado e revistado. Devemos ter igualdade!

Negro explica ao Segurança: _ Isso foi um teste para vermos o tamanho do racismo nos dias da hoje. 


\section{Dengue - Uma Obrigação de Todos}

\section{Personagens:}

$>$ Narrador:

$>$ Juquinha:

$>$ Dudu:

Narrador: Eu vou Ihes contar a história de dois amiguinhos, que sempre estavam juntos por todos os lugares. Eles se chamavam Dudu e Juquinha, eles sempre foram duas crianças felizes, alegres, adoravam brincar como todas as crianças, mas Dudu sempre foi mais desligado, não se preocupava com nada. Já Juquinha era mais interessado no que acontecia na sua cidade e no seu país e o que estava lhe chamando atenção é a questão da dengue. Juquinha resolveu falar com Dudu.

Juquinha: Dudu vi na TV que a dengue está causando muitas vítimas em nossa cidade, que tal a gente reunir nossa turminha e vasculhar o nosso bairro?

Dudu: Juquinha isso não é obrigação nossa e sim do governo que tem que cuidar disso e nós vamos jogar bola que é mais legal, do que ficar de casa em casa catando lata.

Juquinha: Então você não vai me ajudar?

Dudu: Eu não, vou jogar bola que é melhor e você devia vir brincar comigo ao invés de ficar querendo ser adulto antes da hora.

Juquinha: Então eu já vou, vou chamar Luiza e Bianca para ir comigo.

Dudu: Tá, tá, vai me deixar brincar sossegado.

Narrador: Então Juquinha foi convidar suas amiguinhas que toparam ajudar, e eles foram com sacos juntando latas, garrafas tudo o que pudesse acumular água, e também conversavam com as pessoas para cobrir as caixas d'água, os pneus, colocar areia nos pratos de vasos de plantas, não deixar acumular água parada para não ter foco do mosquito. 
Alguns dias depois Juquinha vai a casa de Dudu, porque há muitos dias que eles não se vêem:

Juquinha: O que houve Dudu? Você não tem ido a escola e nem jogado bola.

Dudu: Eu estou doente, estou com dengue.

Juquinha: Mas quando foi isso?

Dudu: Tem uns dois dias, eu estava jogando bola e de repente, comecei a sentir frio e minha cabeça começou a doer. Depois disso só piorei. Agora estou com diarréia e vômito também.

Juquinha: E sua mãe já lhe levou ao médico?

Dudu: Já sim, ele me receitou uns remédios e mandou que eu bebesse muito líquido.

Narrador: Juquinha ficou um pouco com o amigo e depois foi embora. Mas ele se conformou por o amigo estar com dengue e foi onde eles costumavam jogar bola, e encontrou vários focos do mosquito, em copos descartáveis, saquinhos de pipoca e recolheu tudo e jogou no lixo como deveria ter sido feito.Juquinha então voltou a casa de Dudu para lhe contar o que tinha feito.

Juquinha: Dudu fui ao campinho onde a gente joga bola e achei vários focos de mosquito naqueles copos descartáveis, saquinhos de pipoca, eu acho que você foi picado lá.

Dudu: Eu também acho que foi lá. Juquinha você tinha razão, os cuidados com a dengue é obrigação de todos e não só do governo. Foi preciso eu adoecer para ter consciência disso.

Juquinha: Não esquenta meu amigo, ainda tem muita coisa para ser feita.

Dudu: Agora pode contar comigo Juquinha, que eu vou te ajudar.

Juquinha: Claro meu amigo, quanto mais ajuda melhor.

Narrador: E assim fica mais uma lição para nós: A dengue mata! E se nós não ajudarmos o governo fica difícil de combater esse mosquito sozinho. Dengue uma obrigação de todos! 


\section{Chapeuzinho Vermelho em preguiça de estudar}

\section{Personagens:}

$>$ Narrador:

$>$ Chapeuzinho Vermelho:

$>$ Professora:

> Sapo:

$>$ Zezinho:

Narrador : Era uma vez uma menininha muito bonitinha, engraçadinha e muito mas muito preguiçosa. Pois Chapeuzinho não gostava de ir à escola , vivia murmurando.

Chapeuzinho :_oh! Me dá uma preguiça de acordar cedo e ir a escola, quando eu penso naquela aula de português, ai só da vontade de dormir igual a um colega meu ...

Narrador : Quando de repente chapeuzinho no caminho da escola encontra um sapinho que diz:

Sapo: _ Olá, menina, tudo bem? Você está indo para a escola com essa preguiça? Que pena você sabe o que aconteceu comigo? Eu era um menino muito estudioso e não perdia nem uma aula , mas fui reprovado em português e fui transformado nesse bicho asqueroso aqui.

Chapeuzinho :_ Nossa que castigo! Eu não quero ser transformado numa sapa não, o que faço então, me dá um conselho ?

Sapo: _ Desista de estudar, jogue seus livros fora, vamos passear e aproveite que você é preguiçosa e faça parte dos analfabetos dos contos de fada!

Chapeuzinho :_Boa idéia sapinho, mais hoje eu vou para a escola porque tenho prova e se eu faltar minha mãe me dá uma surra.

Sapo:_Chapeuzinho, posso te acompanhar para a escola? 
Chapeuzinho:_Oh..., sim..., claro..., pode vim.

Narrador : E Chapeuzinho vai caminhando com o sapinho estrada fora, para a escola.Chegando lá na escola encontra com a professora que lhe dá uma bronca pelo atraso.

Professora: _ Chapeuzinho porque você atrasou tanto? Não sabe a hora na? E seus livros onde estão?

Chapeuzinho:_ Nossa professora como você está estressada! Não estou afim de sermão.

Professora: _ È assim que responde sua má educada? Você não tem mede de ser reprovada?

Narrador: Chapeuzinho, paralisa e pensa na história de seu amigo que foi transformado em um sapinho e começa a chorar e implorar para a professora.

Chapeuzinho:_ Não, professora tudo menos isso, me perdoe..., desculpe..., eu te amo..., não me reprove.

Professora:_Calma, Chapeuzinho, não chore.

Sapo:_Professora , como faço para voltar a minha forma humana?

Professora: _ Você precisa querer voltar a estudar , para ser alguém na vida e na sociedade, você quer voltar a estudar sapinho?

Sapo:_Sim, quero. Eu prometo voltar a ser um bom aluno.

Narrador: E nessa mesma hora o sapo se transformou em Zezinho que disse:

Zezinho :_Oba! Agora sou eu de novo, voltei minha forma humana.

Narrador: E quando terminou o ano letivo , a professora teve a satisfação de entregar o certificado de aprovados para Chapeuzinho e Zezinho que se esforçaram e conseguiram passar de ano, depois de muitas dificuldades.

TODOS DIZEM : A educação faz parte da nossa vida! 
- Anexo B - Mostrar através de paródias como um grupo desenvolve certas atividades melhor do que individual, é através da ação coletiva que acontece as transformações na sociedade ou na pessoa.

\section{PARÓDIA}

Paródia da música : Então é Natal cantada pela Simone e apresentada no dia do recebimento da bandeira da paz.

Busquemos a paz

Pois o mundo precisa

E só depende de mim e de você

Não podemos deixar

Passar mais um ano

Com violência e problemas

Pra mim e pra você

Busquemos a paz

Pois o mundo precisa

E só encontraremos

Quando o amor renascer

Aleluia,Aleluia,Aleluia. 
- Anexo C- Produção de panfletos, banners, faixas como textos de informação e preservação.

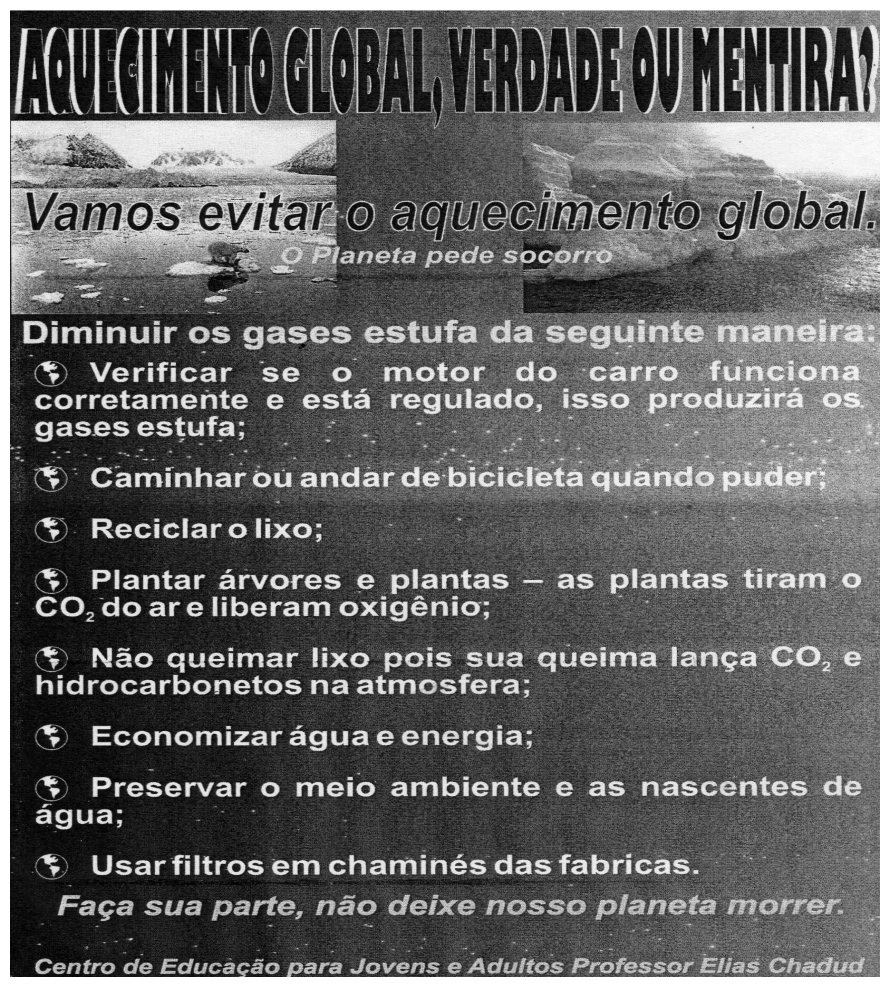

Aquecimento Global: verdade ou mentira?

VAMOS EVITAR O AQUECIMENTO GLOBAL

Diminuir os gases estufa da seguinte maneira:

- Verificar se o motor do carro funciona corretamente e está regulado; isso reduzirá os gases poluentes;

- Caminhar ou andar de bicicleta quando puder;

- Reciclar o lixo;

- Plantar árvores e plantas - as plantas tiram o dióxido de carbono (CO2) do ar e liberam oxigênio;

- Não queimar lixo, pois sua queima lança (CO2) e hidrocarbonetos na atmosfera;

- Economizar água e energia;

- Preservar o meio ambiente e as nascentes de água;

- Usar filtros em chaminés de fábricas;

Faça sua parte, não deixe nosso planeta morrer 